\title{
CLINICAL PROFILE OF PATIENTS WITH EPILEPSY
}

\section{Dilli Ram Kafle and Krishna Kumar Oli}

\begin{abstract}
Epilepsy is a common and diverse disorder with many different causes. Outcomes are varied with $60-70 \%$ of newly diagnosed people rapidly entering remission after starting treatment and 20-30\% developing a drug-resistant epilepsy with consequent clinical and psychosocial distress. It is a Descriptive Cross-sectional study which was conducted in Tribhuvan University Teaching Hospital from January 2013 to January 2014.A total of 150 patients participated in the study. There was statistically significant association between number of seizures before starting medication and the frequency of seizure after starting medication $(\mathrm{p}<0.001)$.
\end{abstract}

Key words: Neurocysticercosis, Epilepsy

\section{Introduction}

Epilepsy is a common and diverse disorder with many different causes. Outcomes are varied with $60-70 \%$ of newly diagnosed people rapidly entering remission after starting treatment, and $20-30 \%$ developing a drug-resistant epilepsy with consequent clinical and psychosocial distress. ${ }^{1}$

About one third of patients with a first unprovoked seizure will have further seizures within five years, and about three quarters of those with two or three unprovoked seizures have further seizures within four years. ${ }^{2}$

Among 50 million people with epilepsy worldwide, $90 \%$ of them are found in developing Countries ${ }^{3}$ and $90 \%$ of these patients are not receiving adequate treatment. They could live normal lives if treated. This huge treatment gap may be due to the limited knowledge, poverty, cultural beliefs, stigma, poor health delivery infrastructure like inadequate supplies of antiepileptic drugs, and shortage of trained health care workers. The prevalence and incidence of epilepsy in Asia is similar to the West but reversible etiologies such as head trauma, infections, stroke, obstetric care are probably more important in Asia. ${ }^{4}$ Epilepsy knows no geographic, social, or racial boundaries and occurs in men and women and affects all ages, but is more frequently diagnosed in infancy, adolescence, and old age. Nepal is one of the poorest countries in the world and it is not uncommon to see huge untreated epilepsy patients in our country. The prevalence rate of epilepsy in Nepal is 7.3 per 1000 population with the treatment gap of over $80 \% .^{5}$ People with low socioeconomic status mostly living in the rural areas are found to be more affected. ${ }^{6}$ Studies have shown that neurocysticercosis and calcified lesions are the commonest radiological findings. ${ }^{7,} 8$ People suffering from epilepsy in our country do not have good quality of life because of their poor epilepsy control.

The present study was undertaken to study clinical profile of patients with epilepsy.

\section{Methodology}

It is a Descriptive Cross-sectional study which was conducted in Tribhuvan University Teaching Hospital from January 2013 to January 2014.

\section{Inclusion Criteria}

All the patients attending to neurology outpatient department and those patients 
admitted to neurology ward and ICU with recurrent seizure.

\section{Exclusion Criteria}

Patients presenting with a history of single seizure ,Patients presenting with a history of multiple seizures within 24 hours without past history of seizure and those who refused to participate in the study.

\section{Statistical Analysis}

Data were entered on the computer by using the SPSS Statistical Software (Version 16; SPSS; Chicago, IL) and were analyzed on the same software. Wherever applicable, the data were presented using both the tabular method and descriptive statistics. The strength of associations had been estimated by linear regression analysis and t- test which were used as appropriate. $\mathrm{P}$ value of less than 0.05 was considered statistically significant.

\section{Result}

The demographic profile of the patients and the clinical characteristics of their seizure are presented in the following table 1.

Table 1. Demographic profile of the study population Baseline Data $(n=150)$

\begin{tabular}{|l|l|}
\hline $\begin{array}{l}\text { Men } \\
\text { Women }\end{array}$ & $76(50.7 \%)$ \\
\hline Age of patients(Year) & $30 \pm 15.36$ \\
\hline $\begin{array}{l}\text { Seizure type } \\
\text { (Focal+ secondarily } \\
\text { generalized) } \\
\text { Generalized }\end{array}$ & $\begin{array}{l}44 \\
106\end{array}$ \\
\hline Age at first seizure (Year) & $47 \pm 17$ \\
\hline $\begin{array}{l}\text { Frequency of seizure( Per } \\
\text { Year) }\end{array}$ & $80.34 \pm 162$ \\
\hline $\begin{array}{l}\text { Duration of seizure before } \\
\text { starting treatment(Year) }\end{array}$ & $2.26 \pm 3.5$ year \\
\hline $\begin{array}{l}\text { Number of seizures before } \\
\text { starting treatment }\end{array}$ & $24 \pm 32.92$ \\
\hline Family history of epilepsy & $14(9.3 \%)$ \\
\hline History of status epilepticus & $24(15.7 \%)$ \\
\hline History febrile & $12(7.8 \%)$ \\
\hline
\end{tabular}

\begin{tabular}{|c|c|}
\hline convulsion & \\
\hline $\begin{array}{l}\text { History of neurological } \\
\text { illness }\end{array}$ & $36(24 \%)$ \\
\hline History of aura & $32(21.3 \%)$ \\
\hline $\begin{array}{l}\text { Documented precipitant for } \\
\text { seizure }\end{array}$ & $15(9.8 \%)$ \\
\hline $\begin{array}{l}\text { Medication } \\
\text { Monotherapy: } \\
\text { Polytherapy }\end{array}$ & $\begin{array}{l}131(87.3 \%) \\
19(12.7 \%)\end{array}$ \\
\hline $\begin{array}{l}\text { Compliance } \\
\text { medication } \\
\text { Regular } \\
\text { Irregular }\end{array}$ & $\begin{array}{l}130(87 \%) \\
20(13 \%)\end{array}$ \\
\hline $\begin{array}{l}\text { EEG } \\
\text { Normal } \\
\text { Abnormal } \\
\end{array}$ & $\begin{array}{l}79(52.7 \%) \\
70(47.3 \%)\end{array}$ \\
\hline $\begin{array}{l}\text { Neuroimaging (CT or MRI) } \\
\text { Normal } \\
\text { Abnormal }\end{array}$ & $\begin{array}{l}63(42 \%) \\
87(58 \%)\end{array}$ \\
\hline
\end{tabular}

A total of 150 patients were included in the study. There were 76 (50.7\%) male and 74(49.3\%) female patients included in the study.

Table 2: Age distribution of study population (years)

\begin{tabular}{|l|l|}
\hline $\begin{array}{l}\text { Age distribution of study } \\
\text { population(years) }\end{array}$ & Number \\
\hline$\leq 20$ & $40(26.7 \%)$ \\
\hline $21-40$ & $80(53.3 \%)$ \\
\hline $41-60$ & $21(14 \%)$ \\
\hline$>60$ & $9(6 \%)$ \\
\hline
\end{tabular}

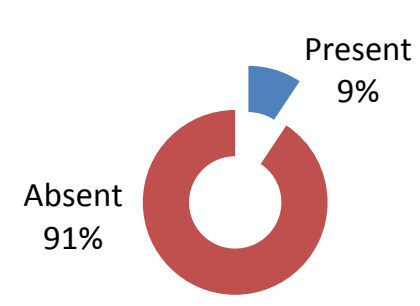

Fig 1. Family history of seizure 
14 (9.3\%) patients reported having a family history of seizure while 136 (89.7\%) patients did not have a family history of epilepsy.

Table 3: Precipitants of seizure

\begin{tabular}{|l|l|l|}
\hline Precipitants & Seizure type & $\begin{array}{l}\text { Number of } \\
\text { patients }\end{array}$ \\
\hline $\begin{array}{l}\text { Sleeep } \\
\text { deprivation }\end{array}$ & GTCS & 6 \\
& $\begin{array}{l}\text { Myoclonic } \\
\text { seizure } \\
\text { Absence } \\
\text { seizure }\end{array}$ & 4 \\
\hline $\begin{array}{l}\text { Alcohol } \\
\text { intake }\end{array}$ & GTCS & 6 \\
\hline $\begin{array}{l}\text { Emotional } \\
\text { stress }\end{array}$ & Partial seizure & 6 \\
\hline Fatigue & Atonic seizure & 2 \\
\hline Hunger & Myoclonic & 1 \\
& seizure & 1 \\
\hline
\end{tabular}

$30(20 \%)$ patients reported having one or more precipitants for their seizure. The precipitants in decreasing order were sleep deprivation, alcohol intake, emotional stress, fatigue and hunger. The presence of precipitants was significantly associated with seizure frequency $(\mathrm{p}=0.004)$

The mean duration of seizure before treatment in years was $2.26 \pm 3.5$. The mean number of

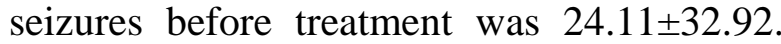
Mean frequency of seizures after treatment per year was $80.34 \pm 162$.

\section{Discussion}

In our study, 30(20\%) patients reported having one or more precipitants for their seizure. The precipitants in decreasing order were sleep deprivation, Alcohol intake, emotional stress, fatigue and hunger. The presence of precipitant was significantly associated with seizure frequency $(p=0.004)$. $\mathrm{E}$ Balamurugan at el also found missing medication, sleep deprivation, fatigue, and emotional stress to be important triggers for seizure onset. $^{1}$
131(87.3\%) patients were on monotherapy. $17(11.3 \%)$ patients were taking 2 drugs while 2(1.3\%) patients were taking 3 drugs. A study conducted in India showed $75.5 \%$ of patients maintained on monotherapy while $24.5 \%$ percent on polytherapy. ${ }^{9}$

While 130(87\%) patients reported taking their medications regularly, only 20(13\%) patients were taking medicine irregularly. Patients who were noncompliant to medication had significantly higher seizure frequency than those patients who were compliant to their medication. $(\mathrm{P}<0.001) 3(2 \%)$ patients reported rash with carbamazepine. 2(1.3\%) patients developed stevens Johnsen syndrome with phenytoin. $1(0.67 \%)$ patient developed hepatitis while on valproic acid. The overall major adverse effect leading to change in current medication was observed in 6 (4\%) of patients.

14(9.3\%) patients reported having a family history of epilepsy in first degree relative. Family history of epilepsy in Nepalese epileptic patients were found to be higher than that found in India (8.4\%) as shown in the study done by Joseph et al. ${ }^{2}$ 116(77.3\%) patients had seizure onset before age 30 in our study. In India Joseph et al. ${ }^{2}$ found $68.9 \%$ of patient to be having seizure onset before age 25.

History of febrile convulsion was given by 12(7.8\%) patients. History of febrile convulsion was statistically associated with seizure frequency $(\mathrm{p}=0.041)$.

There was no statistically significant correlation between the duration of epilepsy before starting medication and the frequency of seizure $(p=0.9)$ in our study.

$30(20 \%)$ patients reported having one or more precipitants for their seizure. The precipitants in decreasing order were sleep deprivation, 
Alcohol intake, emotional stress, fatigue and hunger. The presence of precipitant was significantly associated with seizure frequency $(p=0.004)$. E Balamurugan at el also found missing medication, sleep deprivation, fatigue, and emotional stress to be important triggers for seizure onset. ${ }^{10}$ Aura was reported by $32(21.3 \%)$ of patients. The common aura reported by them was: fear, anger, dizziness, flashes of light, hallucination, tingling sensation and heaviness in head.

131(87.3\%) patients were on monotherapy. $17(11.3 \%)$ patients were taking 2 drugs while 2(1.3\%) patients were taking 3 drugs. While $130(87 \%)$ patients reported taking their medications regularly, only 20(13\%) patients were taking medicine irregularly. Patients who were noncompliant to medication had significantly higher seizure frequency than those patients who were compliant to their medication. $(\mathrm{P}<0.001)$

Nicolas Carpentier et al ${ }^{11} 11$ found in their study that the the rate of nonadherence was $40.9 \%$.Most of the patients in our study were prescribed phenytoin or carbamazepine or valproic acid for their seizures. Some patients were maintained on lamotrigine, oxcarbamazepine or levetiracetam.

\section{Reference}

1. Lois G Kim,Tony L Johnson,Anthony G Marson et al. Prediction of risk of seizure recurrence after a single seizure and early epilepsy: further results from the MESS trial. Lancet Neurol 2006; 5: 317-22.

2. W. Allen Hauser, Stephens S. Rich., Ju R.-J. Lee, et al. Risk of recurrent seizure after two unprovoked seizures. N Engl J Med 1998;338:429-34

3. World Health Organization. Epilepsy fact sheet. Available at: http://www.who.int/ mediacentre/ factsheets/fs999/en/index.html.

4. Chong-Tin TAN. Differences in epilepsy and seizures between Asia and the West. Neurology Asia 2007; $12: 59-60$

5. Rajbhandari KC. Epilepsy in Nepal. Neurol J Southeast Asia 2003;8:1-4.

6. Shaireen Usman, Haroon Rashid Chaudhry, Aftab Asif, et al. Demographic profile of patients with epilepsy in a community clinic. Pak J Med Sci, 2007;23 part II (6) :873-6

7. H. Oscar. Del Brutto, CT findings in neurologically normal adults with a single generalized seizure. Journal of Epilepsy 1994;7 (1):38-40.

8. Gilberto Serrano Ocana, Juan Carlos Ortiz Sablon, Ilen Ochoa Tamayo et al. neurocysticercosis in patients presenting with epilepsy at St Elizabeth's Hospital,Lusikisiki. South African Medical Journal 2009;99 (8):588-91.

9. Jallon $\boldsymbol{P}$. Epilepsy in developing countries. Epilepsia 1997; 38: 1143-51.

10. Balamurugan a, Meena Aggarwal a, Anurag Lamba b, Nitika Dang b, Manjari Tripathi b,* Perceived trigger factors of seizures in persons with epilepsy. Seizure 22 (2013) 743-747

11. Nicolas Carpentier, Jacques Jonas, Solène Frismand, et al. Direct evidence of nonadherence to antiepileptic medication in refractory focal epilepsy. Epilepsia, 54: 20-23.

Corresponding Address: Dr. Dilli Ram Kafle, MBBS, MD, DM Neurology, Nobel Medical College, Biratnagar Nepal; e-mail:dillikafle@yahoo.com 